\title{
Closed Incision Negative Pressure Therapy for Prevention of Groin Wound Complications after Vascular Surgery
}

\author{
Pleger SP*1, Fuhrmann $\mathrm{L}^{1}$, Elzien $\mathbf{M}^{1}$, Böning $\mathrm{A}^{2}$ and Koshty $\mathrm{A}^{1}$ \\ ${ }^{1}$ Department of Vascular Surgery, Jung-Stilling Hospital, Siegen, Germany \\ ${ }^{2}$ Department of Cardiovascular Surgery, University Hospital Giessen, Justus Liebig University Giessen, Germany
}

Received: June 04, 2018; Published: June 12, 2018

*Corresponding author: Sebastian Paul Pleger, Department of Vascular Surgery, Jung-Stilling Hospital, Siegen, Germany, Wichernstrasse 40, 57074 Siegen, Germany

\section{Abstract}

The occurance of wound healing complications (WHCs) in the groin after vascular surgery is a serious medical and financial problem. Surgical site infections (SSIs) in the groin are reported with an incidence between $3 \%$ and $44 \%$. In up to $6 \%$ deep groin infections involve the implanted prosthetic material. Since years case reports and clinical studies report on the effectiveness of the Closed Wound Therapy Incision Negative Pressure (ciNPT) on wound incisions in the groin. The aim of this paper is to review the clinical data of the ciNPT in the treatment of wound incisions in the groin after vascular surgery.

\section{Introduction}

The anatomy of the groin is an important factor in wound healing complications (WHC) after vascular surgery. Due to the presence of lymph vessels and nodes, the proximity to the urogenital organs, as well as its function as a leading access in vascular procedures, postoperatively the groin shows tendency towards wound dehiscence, lymphatic leaks, seroma, hematoma, skin necrosis, tissue infection, and delayed healing [1-7]. Diabetes mellitus, renal insufficiency, overweight, age, malnutrition, operation time and wound length were detected as further risk factors [8]. The incidence of post-surgical site infections (SSIs) in the groin is reported to be between $3 \%$ and $44 \%$. Deep groin infections involving the implanted prosthetic material are present in up to 6\% [4-11]. SSIs are related to morbidity and correlate with complications such as limb ischemia, extremity loss, massive hemorrhage, systemic sepsis, and septic embolization $[1,4,5]$. Long hospital stays with high treatment costs are the consequence of SSIs and the accumulation of severe complications [1].

To deal with SSIs many surgical techniques were applied but only systemic antibiotic therapy showed effective treatment results [3-6,12]. Since the development of the Negative Pressure Wound Therapy (NPWT) in the 1990s by Morykwas and Argenta (USA) as well as Fleischmann (Germany), the wound healing process has been enhanced by this method $[13,14]$. Many case reports and clinical studies reported on the effective use of the NPWT in the treatment of infected wounds as a supplement to surgical debridement and antibiotic therapy; complex open wounds intended for secondary closure; degloving injuries; postoperative sternal wounds; open traumatic injuries; and high-energy trauma wounds [7,14-22]. In the subsequent period successful NPWT was applied on primarily closed wounds with the aim of preventing the wide spectrum of WHC. This new procedure, under the term closed incision negative pressure therapy (ciNPT), has led in abdominal, sternal, traumatic, orthopedic, and plastic surgery incisions to reduction of SSIs since 2010 [23-28].

The success of ciNPT is attributed to its mode of action consisting of protecting the incision from external wound contamination, strengthening the cohesiveness of the wound edges, removing fluids and infectious materials from the wound, decreasing the lateral tension around the incision, and facilitating oxygen saturation and blood microcirculation within the incision area $[12,29,30]$. At present the Prevena ${ }^{\mathrm{TM}}$ Incision Management Therapy System (KCI, an ACELITY Company, San Antonio, Texas, USA) and PICO ${ }^{\text {TM }}$ Single Use Negative Pressure Wound Therapy System (Smith\&Nephew, London, UK) provide the leading ciNPT systems. Prevena ${ }^{\mathrm{TM}}$ consists of a vacuum unit with a battery and a preset negative pressure of -125 mmHg. Additional components are a replaceable exudate collection canister (volume $45 \mathrm{ml}$ ), a polyester fabric interface layer with $0.019 \%$ silver for the control of bioburden within the dressing, a polyurethane foam bolster, and a polyurethane film with acrylic adhesive. A polyurethane shell encapsulates the foam bolster and interface layer providing a closed system [8] (Figure 1). 


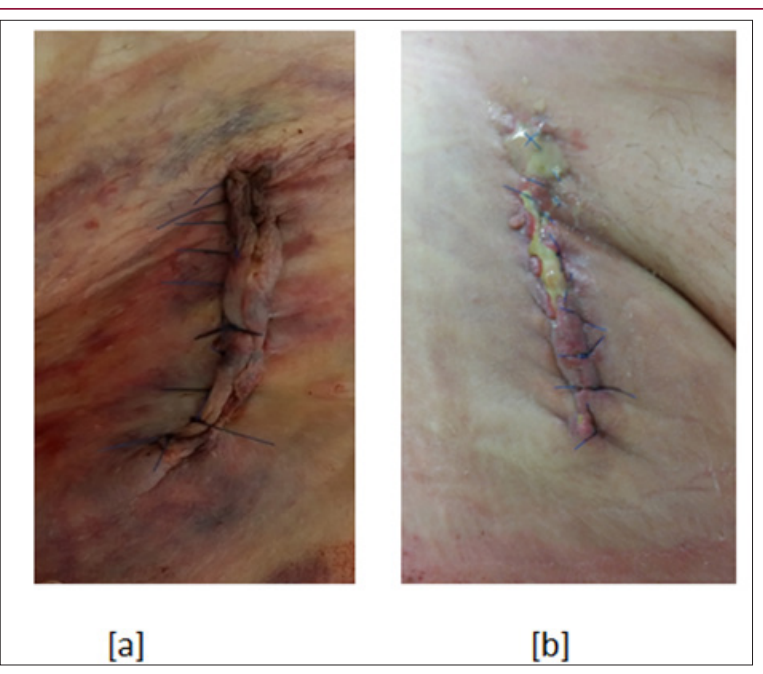

Figure 1: Groin wound complications a) Szilagyi grade I and b) Szilagyi grade II

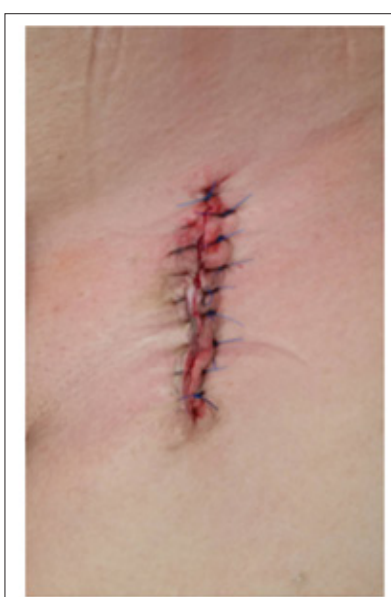

[A]

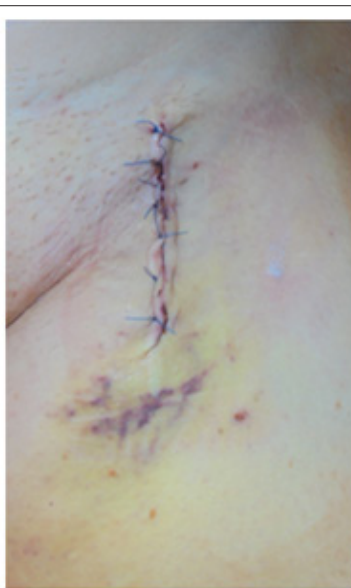

[b]

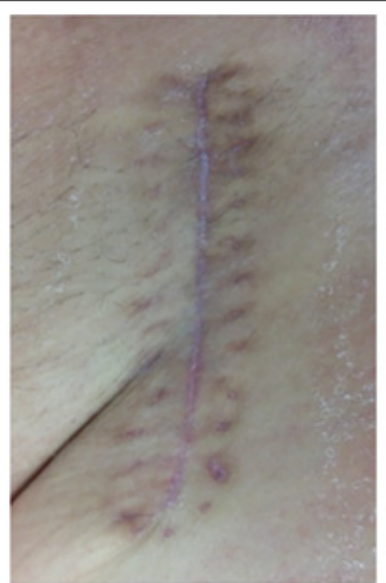

[c]

Figure 2: Primarly closed groin wound a) intraoperative b) on $5^{\text {th }}$ postoperative day and c) on $30^{\text {th }}$ postoperative day.

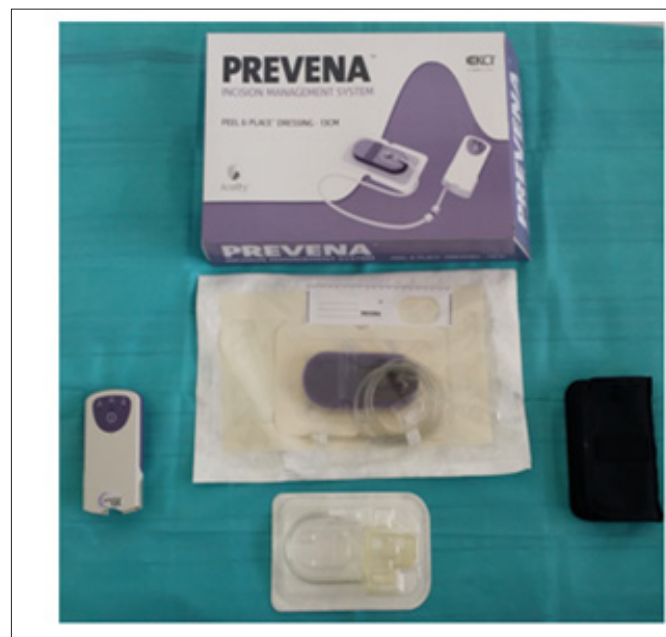

[a]

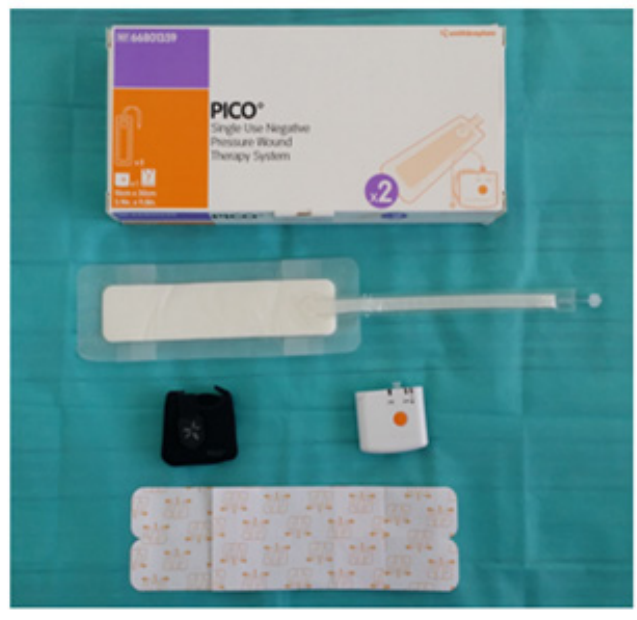

[b]

Figure 3: Components of a) Prevena ${ }^{\mathrm{TM}}$ and b) $\mathrm{PICO}^{\mathrm{TM}}$ 


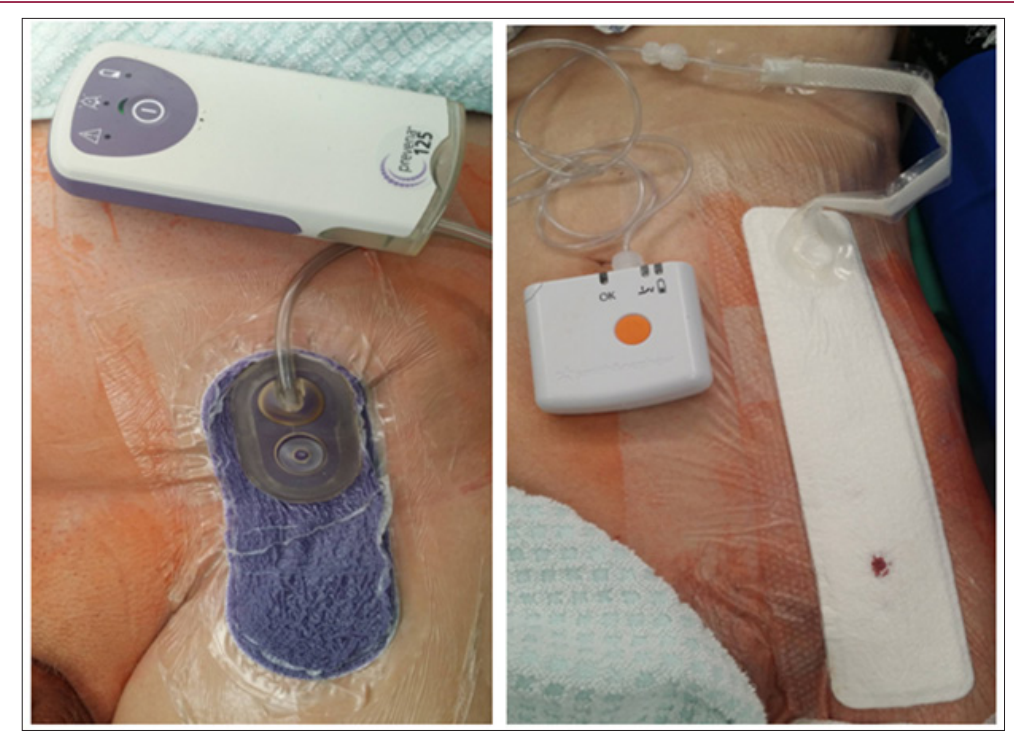

Figure 4: a) Prevena ${ }^{\mathrm{TM}}$ and b) $\mathrm{PICO}^{\mathrm{TM}}$ applied to the groin wound immediately after wound closure.

PICO $^{\text {TM }}$ consists of a battery powered vacuum unit which delivers a negative pressure of $-80 \mathrm{mmHg}$ and a 4 layer multifunction dressing design. Each layer of the dressing has a specific function. The silicone adhesive layer as the nearest to the wound protects the wound environment and decreases pain during the removal. The pioneering airlock layer spreads the negative pressure over the wound surface and enables the movement of secretions through the dressing. The super absorbent core keeps the secretions away from the wound and the top layer film has a high moisture transmission rate. Due to the multi-function dressing almost $80 \%$ of the exudate is lost by evaporation and $20 \%$ remains in the dressing [31] (Table 1). Despite many publications regarding ciNPT only five clinical studies exist which broach the issue of groin wounds after vascular surgeries. In these studies Prevena ${ }^{\text {TM }}$ is the most frequently analyzed ciNPT system [4,8-10,32]. Only one clinical study concerning Prevena ${ }^{\mathrm{TM}}$ is based on randomized design including a subgroup analysis of risk factors and perioperative parameters [30]. Clinical studies concerning $\mathrm{PICO}^{\mathrm{TM}}$ on groin wounds after vascular surgeries are lacking (Figures 2-4).

Table 1: Szilagyi classification of groin wound infections.

\begin{tabular}{|c|c|}
\hline Grade I & Superficial infection that remains restricted on the skin \\
\hline Grade II & $\begin{array}{r}\text { Infiltration of the subcutaneous layer without } \\
\text { participation of the arteria graft }\end{array}$ \\
\hline Grade III & Infection involving the arterial graft \\
\hline
\end{tabular}

\section{Clinical Studies}

The first clinical results regarding the effectiveness of Prevena ${ }^{\mathrm{TM}}$ in patients with groin wounds after vascular surgery were published by Weir. In a pilot study 8 patients were treated with Prevena ${ }^{\mathrm{TM}}$ or a standardized wound dressing respectively after bilateral cut in the groin to perform either a femoro-popliteal bypass, femorofemoral cross over bypasses or Endovascular Aortic Repair (EVAR). After a follow up of 8 months, 2 WHCs (wound dehiscence and hematoma) were noticed in groins treated with Prevena ${ }^{\mathrm{TM}}$. Groin wounds with standardized wound dressing showed 3 WHCs (deep tissue necrosis and seroma) requiring revision surgery. A statistical significance was not revealed [10]. Karl and Woeste examined retrospectively the effect of Prevena ${ }^{\mathrm{TM}}$ in 28 patients. 14 patients with risk factors such as diabetes mellitus, renal insufficiency and revision surgery were treated with Prevena ${ }^{\mathrm{TM}}$ and showed no WHCs on the 7th postoperative day. In the Control-group consisting of 14 patients with approximately the same risk factors treated with a standardized dressing, only one WHC requiring revision surgery was noticed. The patients groups showed no significance regarding either therapy [11].

Matatov et al. retrospectively analyzed Prevena ${ }^{\mathrm{TM}}$ in 90 patients (115 groins) in comparison with either a skin adhesive or absorbent dressing after femoral revascularization, EVAR or Thoracic Endovascular Aortic Repair (TEVAR). The wound evaluation was based on the internationally recognized Szilagyi classification (Table 1). In 40 patients (52 groins) treated with Prevena ${ }^{\text {TM }}$ only 3 wound infections $(6 \%)$ in Szilagyi grade I on $4^{\text {th }}$ and $30^{\text {th }}$ postoperative day were noticed. After the same follow up in the Control-group with 49 patients (63 groins), 19 wound infections (Szilagyi grade I 10, Szilagyi grade II 7, Szilagyi grade III 2) were detected. The analysis showed a significant reduction of wound infections $(p=0.011)$ using Prevena $^{\mathrm{TM}}[4]$.

Koetje et al. examined Prevena ${ }^{\mathrm{TM}}$ in a rectrospective study of 90 patients after femoral endartherectomy and femoral bypass. Preven $\mathrm{a}^{\mathrm{TM}}$ was used on 40 patients and conventional wound dressing on 50 patients. On the $4^{\text {th }}$ postoperative day 7 WHCs were diagnosed in the Prevena ${ }^{\mathrm{TM}}$ group and 6 WHCs in the Control-group. Statistical significance was not proved [32]. Pleger et al. analyzed the effect of Prevena $^{\mathrm{TM}}$ in comparison to a conventional absorbent dressing in a prospective randomized monocentric study entailing 100 patients and 129 groin incisions. Prevena ${ }^{\mathrm{TM}}$ was used on 43 patients (58 groins) and the conventional absorbent dressing on 57 patients (71 groins) after procedures including femoral revascularization, EVAR 
or TEVAR. The wound evaluation was performed using the Szilagyi classification. The wound complication rate in the PREVENA ${ }^{\mathrm{TM}}$ group was $5(8,6 \%)$ and $30(42,3 \%)$ in the Control-group. On days 5 to 7 postoperatively the PREVENA ${ }^{\text {TM }}$-group showed no WHCs and the Control-group 15 WHCs (Szilagyi grade I 5 and Szilagyi grade II 10). On day 30 postoperatively 5 WHCs were noticed in the PREVENA $^{\text {TM }}$-group (Szilagyi grade I 4 and Szilagyi grade II 1) and 15 WHCs in the Control-group (Szilagyi grade I 3, Szilagyi grade II 10 and Szilagyi grade III 2).

Statistical significance was proved in the first $(\mathrm{p}<0.0005)$ and the second evaluation period $(\mathrm{p}=0.023)$. The overall incidence of WHCs in both groups was also statistically significant $(\mathrm{p}<0.0005)$. Wound revision surgeries were performed in only 1 case in the PREVENA $^{\mathrm{TM}}$-group, whereas in 10 cases in the Control-group. The difference between both groups was statistically significant $(p=0.022)$. The additional subgroup analysis proved a significant effect of PREVENA ${ }^{\mathrm{TM}}$ with regard to the wound healing risk factors such as age $(p<0.0005)$, renal insufficiency $(p<0.0005)$, diabetes mellitus $(p<0.0005)$, malnutrition $(p=0.043)$, overweight $(\mathrm{p}<0.0005)$ and perioperative risk factors operation time $(p<0.0005)$, wound length ( $p=0.003)$, hospital stay $(p=0.001)$, and perioperative blood transfusion $(\mathrm{p}=0.004)$ [8].

\section{Conclusion}

Against the background of WHCs in the groin after vascular surgeries which cause serious therapeutical and financial problems for patients, physicians and the financial system, appropriate solutions are needed. Thus the introduction of ciNPT as delivered by Prevena ${ }^{\mathrm{TM}}$ provides a way of preventing severe postoperative healing courses of groin wounds. In comparison to standardized wound dressing Prevena ${ }^{\mathrm{TM}}$ shows in two studies an significant reduction of WHCs in the groin after vascular surgeries $[4,8]$. Furthermore, a significant effect of Prevena ${ }^{\mathrm{TM}}$ could be shown in revision surgeries as well as in wound healing risk factors and perioperative risk factors [8]. Despite the significant results in primary incision groin wounds the effect of ciNPT on revision groin wounds is not yet known. In future prospective clinical studies are needed to investigate the effect of ciNPT on groin wounds after revision surgeries. First promising interim results from the ongoing Aachen Incision Management System (AIMS-) Trial show a significant reduction of WHCs in patients with prior incisions in the groin using Prevena ${ }^{\mathrm{TM}}$ (WHCs: PREVENA ${ }^{\mathrm{TM}}$ 21,7\%; ControlGroup 50\%, p< 0.001) [33]. In summary, it can be stated that ciNPT is an effective therapy to avoid WHCs in the groin after vascular surgeries.

\section{References}

1. Swinnen J, Chao A, Tiwari A, Crozier J, Vicaretti M, et al. (2010) Vertical or transverse incisions for access to the femoral artery: a randomized control study. Ann Vasc Surg 24(3): 336-341.

2. Ploeg AJ, Lardenoye JW, Peeters MP, Hamming JF, Breslau PJ (2009) Wound complications at the groin after peripheral arterial surgery sparing the lymphatic tissue: a double-blind randomized clinical trial. Am J Surg 197(6): 747-751.
3. Stewart AH, Eyers PS, Earnshaw JJ (2007) Prevention of infection in peripheral arterial reconstruction: a systematic review and metaanalysis. J Vasc Surg 46(1): 148-155.

4. Matatov T, Reddy KN, Doucet LD, Zhao CX, Zhang WW (2013) Experience with a new negative pressure incision management system in prevention of groin wound infection in vascular surgery patients. J Vasc Surg 57(3): 791-795.

5. Engin C, Posacioglu H, Ayik F, Apaydin AZ (2005) Management of vascular infection in the groin. Tex Heart Inst J 32(4): 529-534.

6. Giovannacci L, Eugster T, Stierli P, Hess P, Gurke L (2002) Does fibrin glue reduce complications after femoral artery surgery? A randomised trial. Eur J Vasc Endovasc Surg 24(3): 196-201.

7. Dosluoglu HH, Loghmanee C, Lall P, Cherr GS, Harris LM, et al. (2010) Management of early ( $<30$ day) vascular groin infections using vacuumassisted closure alone without muscle flap coverage in a consecutive patient series. J Vasc Surg 51(5): 1160-1166.

8. Pleger SP, Nink N, Elzien M, Kunold A, Koshty A, et al. (2018) Reduction of groin wound complications in vascular surgery patients using closed incision negative pressure therapy (ciNPT): a prospective, randomised, single-institution study. Int Wound J (1): 75-83.

9. de Lissovoy G, Fraeman K, Hutchins V, Murphy D, Song D, et al. (2009) Surgical site infection: incidence and impact on hospital utilization and treatment costs. Am J Infect Control 37(5): 387-397.

10. Weir G (2014) The use of a surgical incision management system on vascular surgery incisions: a pilot study. Int Wound J 11: 10-12.

11. Karl T, Woeste S (2013) Prevention of inguinal wound healing disorders in vascular surgery. Results of using an epidermal negative pressure system (Prevena). Gefasschirurgie 18: 120-125.

12. Horch RE (2015) Incisional negative pressure wound therapy for highrisk wounds. J Wound Care 24: 21-28.

13. Morykwas MJ, Argenta LC, Shelton-Brown EI, McGuirt W (1997) Vacuumassisted closure: a new method for wound control and treatment: animal studies and basic foundation. Ann Plast Surg 38(6): 553-562.

14. Stannard JP, Robinson JT, Anderson ER, McGwin G, Volgas DA, et al. (2006) Negative pressure wound therapy to treat hematomas and surgical incisions following high-energy trauma. J Trauma 60(6): 13011306.

15. Banwell PE, Musgrave M (2004) Topical negative pressure therapy: mechanisms and indications. Int Wound J 1(2): 95-106.

16. Meara JG, Guo L, Smith JD, Pribaz JJ, Breuing KH, et al. (1999) Vacuumassisted closure in the treatment of degloving injuries. Ann Plast Surg 42(6): 589-594.

17. Gustafsson R, Johnsson P, Algotsson L, Blomquist S, Ingemansson R (2002) Vacuum-assisted closure therapy guided by C-reactive protein level in patients with deep sternal wound infection. J Thorac Cardiovasc Surg 123(5): 895-900.

18. Wongworawat MD, Schnall SB, Holtom PD, Moon C, Schiller F (2003) Negative pressure dressings as an alternative technique for the treatment of infected wounds. Clin Orthop 414: 45-48.

19. DeFranzo AJ, Argenta LC, Marks MW, Molnar JA, David LR, et al. (2001) The use of vacuum-assisted closure therapy for the treatment of lowerextremity wounds with exposed bone. Plast Reconstr Surg 108(5):11841191.

20. Scherer LA, Shiver S, Chang M, Meredith JW, Owings JT (2002) The vacuum assisted closure device: a method of securing skin grafts and improving graft survival. Arch Surg 137(8): 930-934.

21. Morton N (2004) Use of topical negative pressure therapy in postoperative dehisced or infected wounds. J Wound Care 13(8): 346348 . 
22. Leininger BE, Rasmussen TE, Smith DL, Jenkins DH, Coppola C (2006) Experience with Wound VAC and Delayed Primary Closure of Contaminated Soft Tissue Injuries in Iraq. J Trauma 61(5): 1207-1211.

23. Grauhan O, Navasardyan A, Tutkun B, Hennig F, Müller P, et al. (2014) Effect of surgical incision management on wound infections in a poststernotomy patient population. Int Wound J 11: 6-9.

24. Pachowsky M, Gusinde J, Klein A, Lehrl S, Schulz-Drost S, et al. (2012) Negative pressure wound therapy to prevent seromas and treat surgical incisions after total hip arthroplasty. Int Orthop 36(4): 719-722.

25. Conde-Green A, Chung TL, Holton LH, Hui-Chou HG, Zhu Y, Wang $\mathrm{H}$, et al. (2013) Incisional Negative-Pressure Wound Therapy versus conventional dressings following abdominal wall reconstruction. A comparative study. Ann Plast Surg 71(4): 394-397.

26. Stannard JP, Volgas DA, McGwin G, Stewart RL, Obremskey W, et al (2012) Incisional negative pressure wound therapy after high-risk lower extremity fractures. J Orthop Trauma 26(1): 37-42.

27. Anglim B, Oconnor H, Daly S (2015) Prevena ${ }^{\mathrm{TM}}$, negative pressure wound therapy applied to closed Pfannenstiel incisions at time of caesarean section in patients deemed at high risk for wound infection. J Obstet Gynaecol 35(3): 255-258.

(C) (i) This work is licensed under Creative

Submission Link: https://biomedres.us/submit-manuscript.php
28. Galiano RD, Hudson D, Shin J, van der Hulst R, Tanaydin V, et al. (2018) Incisional Negative Pressure Wound Therapy for Prevention of Wound Healing Complications Following Reduction Mammaplasty. Plast Reconstr Surg Glob Open 6(1): e1560.

29. Wilkes RP, Kilpadi DV, Zhao Y, Kazala R, McNulty A (2012) Closed incision management with negative pressure wound therapy (CIM): biomechanics. Surg Innov 19(1): 67-75.

30. Karlakki S, Brem M, Giannini S, Khanduja V, Stannard J, et al. (2013) Negative pressure wound therapy for management of the surgical incision in orthopaedic surgery: A review of evidence and mechanisms for an emerging indication. Bone and Joint Research 2(12): 276-284.

31. Malmsjö M, Huddleston E, Martin R (2014) Biological Effects of a Disposable, Canisterless Negative Pressure Wound Therapy System. Eplasty 14: e15.

32. Koetje JH, Ottink KD, Feenstra I, Fritschy WM (2015) Negative Pressure Incision Management System in the Prevention of Groin Wound Infection in Vascular Surgery Patients. Surgery Research and Practice.

33. Gombert A, Babilon M, Langer S (2017) Incision management systems for reduction of inguinal wound complications in vascular surgery. Vascular surgery 22: 542-547.

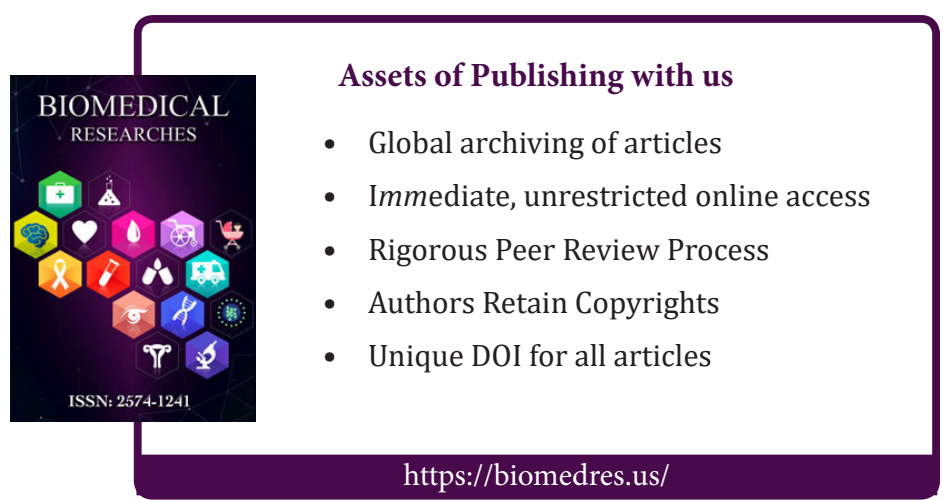

